\title{
Structural integrity of shot peened Ti6Al4V specimens under fretting fatigue
}

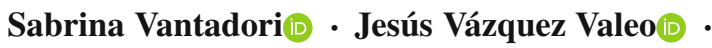 \\ Andrea Zanichelli(i) - Andrea Carpinteri • \\ Raimondo Luciano
}

Received: 2 December 2020 / Accepted: 9 February 2021 / Published online: 5 March 2021

(C) The Author(s) 2021

\begin{abstract}
In the present paper, an experimental campaign performed on shot peened Ti6Al4V specimens under fretting fatigue, available in the literature, is simulated by using the Carpinteri et al. criterion. The experiments examined were carried out using a standard configuration, that is, a cylinder against a flat specimen. The fretting loading is a combination of low-cycle fatigue and high-cycle fatigue, and the corresponding stress field is determined by a FE analysis. A theoretical law is applied to describe the relaxed residual stress produced by shot peening treatment and fatigue loading.
\end{abstract}

S. Vantadori $(\varangle) \cdot$ A. Zanichelli · A. Carpinteri Department of Engineering and Architecture, University of Parma, Parco Area delle Scienze 181/a, 43124 Parma, Italy e-mail: sabrina.vantadori@unipr.it

A. Zanichelli

e-mail: andrea.zanichelli@unipr.it

A. Carpinteri

e-mail: andrea.carpinteri@unipr.it

J. Vázquez Valeo

Departamento de Ingeniería Mecánica y Fabricación, Universidad de Sevilla, Camino de los Descubrimientos s/n, 41092 Sevilla, Spain

e-mail: jesusvaleo@us.es

R. Luciano

Department of Engineering, University of Naples

Parthenope, Centro Direzionale Isola C4, 80143 Naples,

Italy

e-mail: raimondo.luciano@uniparthenope.it
Keywords Crack initiation - Critical plane $\cdot$ FE model $\cdot$ Structural assessment

\section{Introduction}

Fretting is generally defined as follows: (i) a wear phenomenon occurring between two surfaces having an oscillatory relative motion of small amplitude, and (ii) such a motion, usually tangential, is between two surfaces in contact (International ASM 2017). Note that, according to such a definition, the expression fretting refers only to the nature of motion (that is, oscillatory and with small amplitude) without reference to the damage produced.

It is more convenient to specify the cause of such a motion, and, therefore, to use the expression fretting wear as fretting for which the small displacements are a consequence of external vibrations, affecting at least one of the two contacting parts, and fretting fatigue as fretting for which the small displacements are a consequence of cyclic deformations, at least in one of the two contacting parts (Kapsa 2011).

In fretting cases, it should be considered the relative displacement as compared to the contact size, in order to identify the limit between fretting and reciprocating sliding. To such an aim, let us consider a "ball on a flat contact surface" situation, as an example. Various modes of fretting can be distinguished related to the type of relative motion, as is described in the following. 
More precisely, by representing the contact force against the tangential displacement range, $2 \delta$, between two points in the undeformed region of each body (Fig. 1), and by defining the parameter $e$ as the ratio between the displacement amplitude $\delta$ and the radius $a$ of the Hertzian contact area, three domains can be distinguished (Kapsa 2011; Fouvry et al. 1995; Zhou et al. 2000) (Fig. 1): partial slip and gross slip are located in a domain characterised by $e<1$, when a part of the wear scar is never in contact with the environment, whereas reciprocating sliding is located in a domain characterised by $e>1$, when the entire wear scar is in contact with the environment.

From a wear phenomenological point of view, damage is associated with contact stress and sliding conditions (Kapsa 2011):

(i) When the contact is composed of a stick area and a slip area (Fig. 1), damage is mainly due to cracking phenomena (crack initiation and propagation) as a consequence of vibrations/cyclic deformation effects in the material, inducing time-varying contact stress;

(ii) When the contact is whole sliding (Fig. 1), that is, both in gross slip and in reciprocating sliding, damage is mainly due to wear phenomena as a consequence of matter loss produced by solid and interfacial matter interactions.

Therefore, for partial slip cases, fatigue theories and fatigue criteria can be used for damage estimations (Hamada et al. 2020), whereas the concept of dissipated energy can be used for gross slip and reciprocating sliding cases (Liu et al. 2020).

Fretting fatigue has been identified as the cause of serious damage in dovetail connections of aero engines (Korsunsky 2017), where crack initiation and propagation take place in frictional contacting surfaces. Shot peening is a well-known method employed to improve fatigue resistance of metals and metal alloys of contacting surfaces.

Although some attempts to simulate the above complex configuration (i.e. dovetail connection) are available in the literature (Papanikos and Meguid 1994; Papanikos et al. 1998; Chan et al. 2001a,b; Rajasekaran and Nowell 2006; Calcaterra and Golden 2006; Murugesan and Mutoh 2014; Yang et al. 2018; Mangardich et al. 2019; Pereira et al. 2020; Sun et al. 2020; Sunde et al. 2021; Yuan et al. 2021), experimental investigation of full scale models still provides more realistic information, even if such an investigation is costly and lengthy. In this context, it seems important to the authors a deep understanding of fretting fatigue process but analysing a simpler configuration, where material and treatment of the tested specimens are those typically employed in aero engine manufacturing.

Therefore, in the present paper, an experimental testing on the standard configuration (a cylinder against a flat specimen) (Araújo and Nowell 2009) is examined and simulated by applying the Carpinteri et al. criterion for fretting fatigue (Carpinteri et al. 2019; Vantadori et al. 2019, 2020a, b; Vantadori and Zanichelli 2020; Zanichelli and Vantadori 2020). The specimens, provided by Rolls-Royce, were made by Ti6Al4V and shot peened according to Rolls-Royce specifications (Araújo and Nowell 2009). The fretting loading considered in tests was a combination of low-cycle fatigue (LCF) and high-cycle fatigue (HCF), and represented the actual loading condition acting in correspondence to aero engine dovetail connections.

Ti6Al4V alloy presents an $(\alpha+\beta)$ microstructure resulting from a dendritic microstructure $\beta$, produced during solid state cooling. It is one of the most commonly used titanium alloys, since it features a good balance between the mechanical properties of strength (especially at temperature greater than $200^{\circ} \mathrm{C}$ ) and ductility. Such an alloy was originally developed for lightweight and high-strength applications in the aerospace industry, but nowadays it is also used in marine, power generation, and offshore ones.

In the aircraft industry, Ti6Al4V is mainly used for manufacturing disk and fan blades of gas turbines. The material has a high friction coefficient $(\sim 0.6)$, which makes it very sensitive to fretting: for such a reason, many studies are focused to investigate its behaviuor against fretting.

\section{Fretting fatigue tests under partial slip regime: the experimental campaign examined}

The experimental campaign here summarised, and then simulated, was performed at the University of Oxford on specimens obtained by coring a real engineering component, represented by an aero engine provided by Rolls-Royce (Araújo and Nowell 2009). More precisely, the specimens were manufactured by starting from both fan blade and disc of the above aero engine, made of Ti6Al4V alloy. Fretting fatigue tests under par- 
Fig. 1 Contact force vs relative displacement range for a ball on flat contact: various situations of sliding conditions

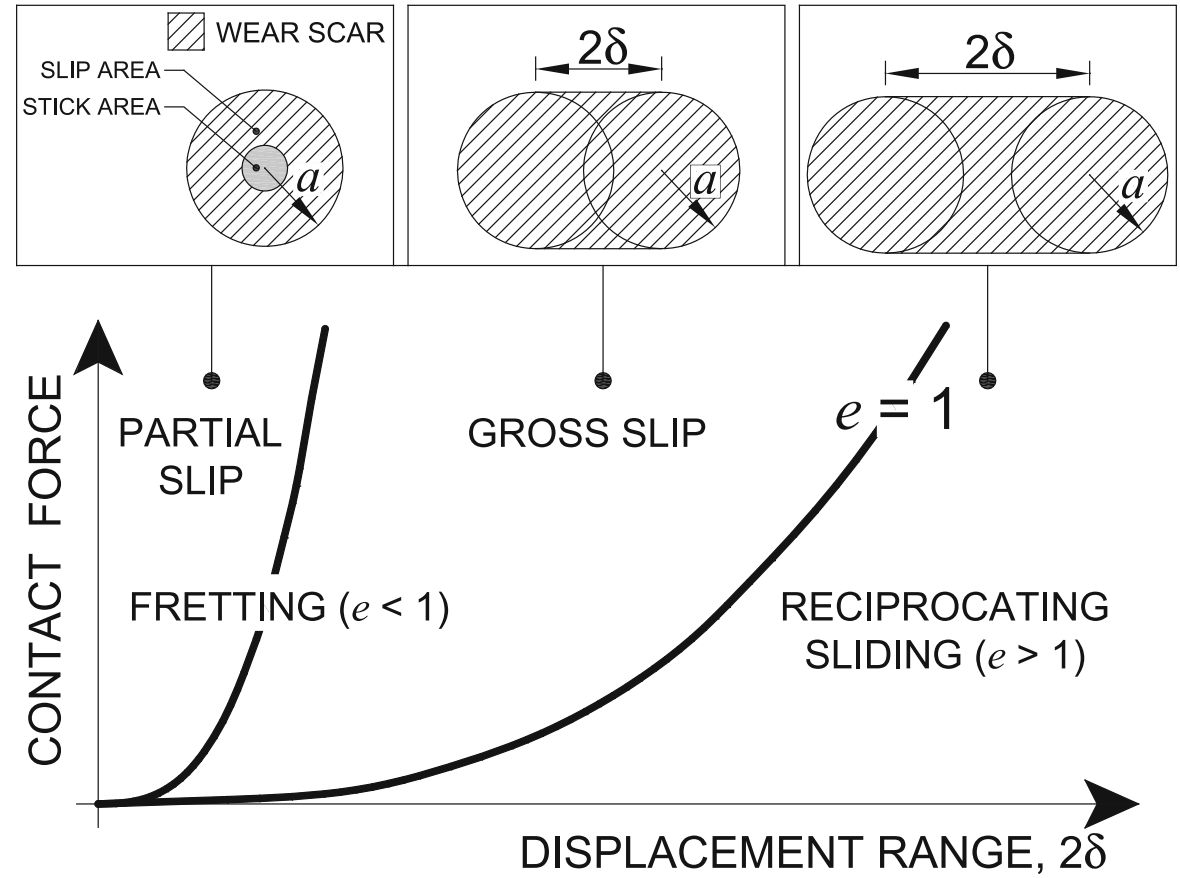

2.2 Specimens and pads: shot peening treatment

The whole surfaces of the specimens and pads were shot peened by Metal Improvement Ltd. according to Rolls-Royce specifications, but no details were included in Araújo and Nowell (2009).

A surface roughness of $2 \mu \mathrm{m}$ r.m.s. was measured for both specimens and pads. The coefficient of friction, $\mu$, computed according to the technique developed by Hills and Nowell (1994), was equal to 0.55.

\subsection{Testing rig}

A two-actuator fretting rig was employed. Figure 3 shows the fixed and the moveable jaws that held the specimen, being the moveable jaw connected to the first actuator: such an actuator applied the LCF loading to the specimen by means of the cyclic bulk force, $P$, measured through a load cell linked with such an actuator.

The two cylindrical pads, attached to the carrier, were clamped against the specimen by means of the cylinder of a hydraulic pump: the pump applied a constant normal loading to the specimen by means of two contact forces, $N$, measured by the pressure of the oil in the hydraulic line. The HCF loading was applied to 
Table 1 Experimental campaign examined: loading conditions and fatigue lives

\begin{tabular}{llllllr}
\hline Series no. & Component & $p_{0}(\mathrm{MPa})$ & $Q_{\max } / N$ & $\sigma_{B, \max }(\mathrm{MPa})$ & $a(\mathrm{~mm})$ & $N_{\text {exp }}(\mathrm{cycles})$ \\
\hline 1 & Blade & 500 & 0.23 & 265 & 1.06 & $22,651,200$ \\
2 & Disc & 500 & 0.23 & 265 & 1.06 & $21,859,200$ \\
3 & Blade & 500 & 0.45 & 265 & 1.06 & $28,51,200$ \\
4 & Blade & 750 & 0.20 & 400 & 1.59 & $4,687,200$ \\
5 & Disc & 750 & 0.10 & 600 & 3.59 & $6,228,000$ \\
6 & Disc & 750 & 0.20 & 300 & 1.59 & $5,788,800$ \\
\hline
\end{tabular}

Fig. 3 Fretting fatigue rig

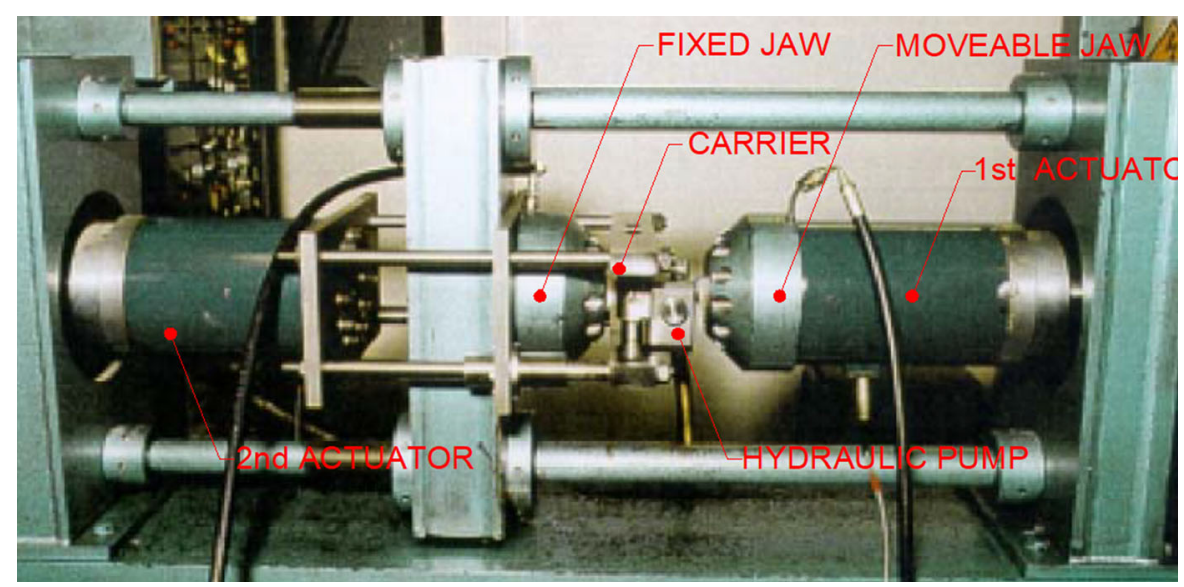

the specimen by the second actuator, and a load cell connected to such an actuator was used to measure one of the two cyclic forces, $Q$.

\subsection{Loading configurations}

A reference loading block was applied many times during testing, up to the complete specimen failure. More precisely, such a loading block, represented in Fig. 4, consisted of the following steps, here described according to the application order:

(1) The constant force $N$ was applied;

(2) The bulk force $P$ was made to increase from 0.1 $\mathrm{kN}$ to its maximum value, $P_{\max }$, in a time interval equal to $6 \mathrm{~s}$;

(3) The tangential force $Q$, related to each pad, was made to vary cyclically for 7200 times from its maximum value, $Q_{\max }$, to the minimum one, $Q_{\min }$, with a loading ratio equal to -1 . The waveform was sinusoidal, characterised by a frequency equal to $40 \mathrm{~Hz}$. Note that, during this step, $P$ was taken as a constant and equal to $P_{\max }$;
(4) The bulk force $P$ was made to decrease from $P_{\max }$ to $0.1 \mathrm{kN}$ in a time interval equal to $6 \mathrm{~s}$, and taken equal to such a value for $6 \mathrm{~s}$.

Such a reference loading block, characterised by the LCF loading, due to the bulk force $P$, and by the HCF loading, due to the tangential force $Q$, may be assumed to be composed by 7200 loading cycles.

It is worth noticing that, according to Araújo and Nowell (2009), the influence of the LCF loading on the estimated fatigue life is negligible. More precisely, an analysis using the Fatemi-Socie multiaxial fatigue parameter in conjunction with the Palmgren-Miner linear damage rule showed that the damage produced by the HCF loading accounted more than $99 \%$ of the evaluated total fatigue life. Such a statement justifies the approach used here to simulate the experimental campaign examined (see Sect. 5).

The six loading conditions analysed are listed in Table 1 in terms of: maximum value of the theoretical Hertzian contact pressure distribution $p_{0}$, ratio $Q_{\max } / N$, and maximum value $\sigma_{B, \max }$ of the stress produced in the specimen net-section when the bulk force 
Fig. 4 Reference loading block

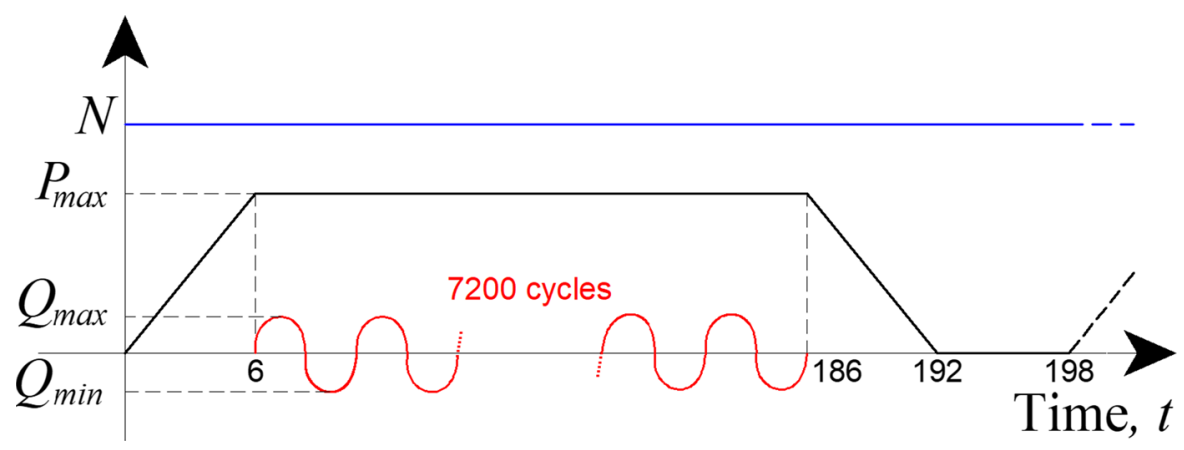

is equal to $P_{\max }$. The theoretical contact semi-width value $a$ is also reported for each loading condition.

Generally, three tests were performed for each loading condition (Series from No. 1 to No. 6 in Table 1).

\subsection{Experimental results}

The experimental fatigue fretting lives are listed in Table 1.

By examining the specimens after testing (Araújo and Nowell 2009), cracks (that is, the main primary one and the secondary ones) were observed to start from a surface region both in the fretted zone and close to the trailing edges and, due to the symmetrical configuration of the testing rig, on both sides of the specimen. More precisely, multiple secondary cracks grew along a direction towards the main primary crack, with an oblique orientation. For one specimen of the Series No.5, the orientation of the main primary crack was initially equal to $10^{\circ}$, and then changed its orientation to about $21^{\circ}$ (Araújo and Nowell 2009). Particles detachments were also observed. No other details are reported in Araújo and Nowell (2009).

\section{Theoretical law for relaxed residual stress}

As is well-known, one of the effects of the shot peening treatment is to produce compressive residual stresses in a superficial material layer of the order of $0.1-0.5 \mathrm{~mm}$. Under cyclic loading, residual stress relaxation may be observed.

A theoretical law to evaluate the relaxed residual stress profile in the above situation has been recently proposed by some of the present authors (Vantadori and Zanichelli 2020). More precisely, the self-equilibrated stress profile, formulated by observing the experimental evidence (Araújo and Nowell 2009; Farrahi et al. 1995; Gao et al. 2002; Higounenc 2005; Sabelkin et al. 2005; Kirk 2014), is idealised as follows:

(a) The value of the stress in correspondence to the surface is assumed to be equal to zero;

(b) Then, the compressive stress follows a linear trend up to its maximum value, reached at a depth equal to $0.28 D_{c}$, being $D_{c}$ a depth computed according to point (d) below;

(c) Such a maximum value is assumed to be equal to $\frac{2}{3} \sigma_{y}$

(d) Successively, the compressive stress follows a linear trend up to a depth $D_{c}$, in correspondence of which the stress is equal to zero. $D_{c}$ is here empirically evaluated to be equal to $0.8 \phi_{\text {shot }}$, where $\phi_{\text {shot }}$ is the shots diameter;

(e) Over $D_{c}$, a compensatory tensile stress distribution is adopted in order to have a self-equilibrated residual stress distribution.

Note that residual stresses are constant and, therefore, affect the fatigue behaviour of the material in the same way as a static loading or the mean value of a cyclic loading applied to the specimen.

The theoretical law proposed in Vantadori and Zanichelli (2020) is useful particularly when no details concerning the actual residual stress depth profiles are available, as occurs in the present case.

\section{Numerical evaluation of the specimen stress field}

The commercial software ANSYS is here used to simulate the fretting fatigue tests described in Sect. 2.

Based on the satisfactory results obtained in some previous research works (Vázquez et al. 2016, 2019; Martín et al. 2020), a plain strain condition is assumed 
Fig. 5 Numerical model: a schematisation of the testing rig, b model discretisation, and $\mathbf{c}$ reference loading block implemented in the $\mathrm{FE}$ analysis
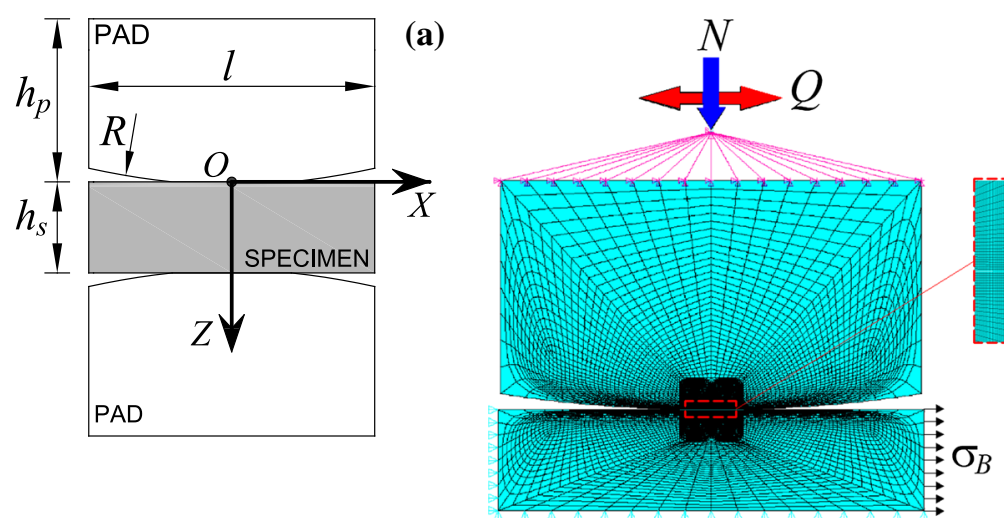

(b)

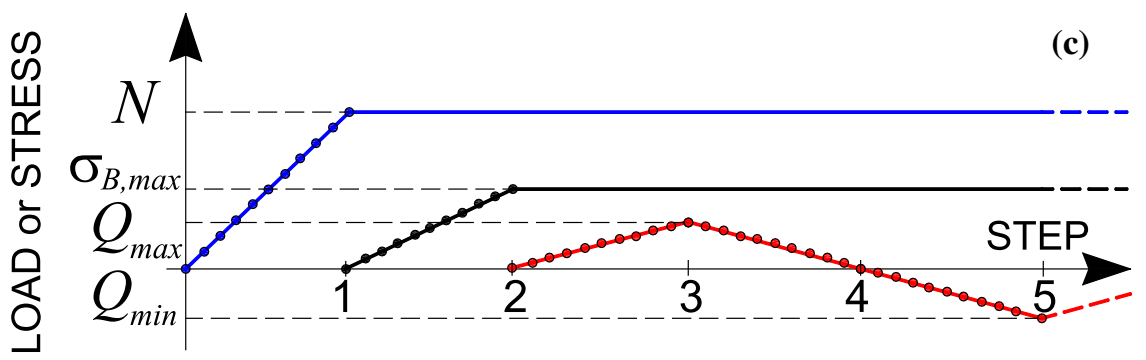

for the numerical model here employed, schematised in Fig. 5a. Due to the symmetry condition that characterises such a model, only a half of the specimen is discretised (Fig. 5b).

Each pad has a radius $R=68 \mathrm{~mm}$, which is equal to that of the pads of the testing rig, whereas the height $h_{p}$ is set equal to ten times the theoretical Hertzian contact semi-with $a$ (see Table 1 ). Such a value of $h_{p}$ is adopted in order to avoid size effect due to pads geometry: as a matter of fact, such a value is in agreement with the height of the testing rig pads which is long enough to have a half-space behaviour for the pads. The specimen height $h_{s}$ is equal to that of the tested specimens which is equal to $11 \mathrm{~mm}$. In addition, the length of both specimen and pads is set equal to $l=20 a$, to also avoid possible boundary conditions effects.

Two material behaviours are alternatively implemented in the numerical models for both the pad and the specimen, the mechanical properties of the Ti6Al4V alloy being shown in Sect. 2.1. The first behaviour is the linear elastic behaviour. The second one is the elastic-plastic behaviour characterised by a kinematic hardening, where the cyclic stress-strain relationship is defined by the Ramberg-Osgood equation:

$\varepsilon=\frac{\sigma}{E}+\left(\frac{\sigma}{K^{\prime}}\right)^{\frac{1}{n^{\prime}}}$ with $K^{\prime}=852 \mathrm{MPa}$ and $n^{\prime}=0.074$ (1)(Boller and Seeger 1987).

A linear formulation is adopted for all the finite element types employed in the discretisation: PLANE182, CONTA171 and TARGE169. The mesh density is fine enough to capture the stress gradient in the vicinity of the surface contact region. The part of the surface interested by the contact is characterised by 512 nodes. The discretisation used is shown in Fig. 5 b.

The contact algorithm employed in the simulations is the Augmented Lagrangian Method, which produces a good ratio between accuracy in contact results and CPU times (Simo and Laursen 1992). Using such an algorithm, most of the defaults values and options implemented in the commercial software ANSYS are used, that is: automatic stiffness updating, size of Pinball region, maximum allowable penetration, and many others. Moreover, normal and tangential contact penalty stiffness factor values equal to 2 and 5 times the software default value (equal to 1.0), respectively, are used. Such values allow us to simulate the steep stress gradients produced at the contact surface, with a satisfactory accuracy.

Note that the coefficient of friction is equal to 0.55 and, due to its high value, an unsymmetric iterative solver is required in order to achieve a good numerical 
convergence. The convergence analysis is performed with respect to the peak value of the contact shear stress distribution. As a matter of fact, this distribution has a stepped gradient near the peak value, and thus is suitable as a convergence criterion.

The loads $N$ and $Q$ are applied on the top surface of the pad via a master node, whereas the bulk load is directly applied as a surface load on the specimen $\left(\sigma_{B}\right.$ in Fig. 5b).

In order to numerically simulate the experimental load application order, and according to the reference loading block presented in Sect. 2.4, the following procedure is applied, as is schematised in Fig. 5c:

(1) In the first loading step, the normal load is increased up to its constant value $N$;

(2) In the second step, the bulk stress $\sigma_{B}$ is increased up to its maximum value $\sigma_{B, \max }$;

(3) In the loading step No. 3 , the tangential force $Q$ is made to vary cyclically between $Q_{\min }$ and $Q_{\max }$. Three complete loading cycles are required to obtain a stabilised solution.

Note that each of the above loading ramp is characterised by ten loading sub-steps, the time interval associated with each of them being equal to $0.0025 \mathrm{~s}$.

In order to implement the residual stress in the numerical model, two different approaches are used, depending on the material behaviour assumed. For a linear elastic material behaviour, the stress field computed by FEA is directly added to the residual stress one presented in Sect. 3, by exploiting the superposition principle. For elastic-plastic material behaviour, the residual stress (in Sect. 3) is included in the numerical model as an initial stress state at each finite element centroid.

According to the theoretical law in Sect. 3, the residual stress against depth is shown in Fig. 6. Note that the shots diameter $\phi_{\text {shot }}$, needed to compute $D_{c}$, was not provided by Rolls-Royce. According to Araújo and Nowell (2009), $\phi_{\text {shot }}$ is typically in the range 0.1-1.0 $\mathrm{mm}$ : therefore, a value of $0.5 \mathrm{~mm}$ is herein assumed.

For each loading condition listed in Table 1, the normalised surface contact shear stress distribution, $q(x)$, in correspondence of $Q=Q_{\min }$ and $Q=Q_{\max }$ are shown in Fig. 7. Figure 7a shows the results obtained via a linear elastic analysis; in such a situation, residual stresses are not implemented in the numerical model. In Fig. $7 b$, the distribution $q(x)$ is plotted for elastic-

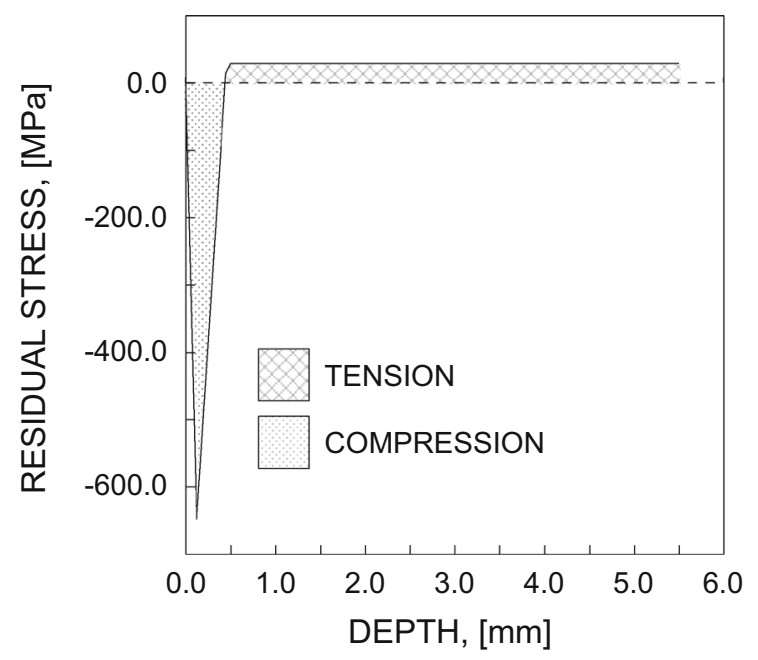

Fig. 6 Residual stress profile vs depth implemented in the numerical model

plastic analysis with residual stresses included in the numerical model.

\section{Evaluation of crack initiation path and fatigue life}

The multiaxial critical plane-based criterion for fretting fatigue, by Carpinteri et al. (2019), Vantadori et al. (2019), Vantadori et al. (2020a), Vantadori et al. (2020b), Vantadori and Zanichelli (2020), Zanichelli and Vantadori (2020), is here applied to simulate the experimental campaign described in Sect. 2. The stress field in the specimens, that is, the input data for the above criterion, is computed both by a linear elastic analysis in conjunction with the superposition principle and by an elastic-plastic analysis, as is discussed in Sect. 4.

\subsection{The Carpinteri et al. criterion for fretting fatigue}

The critical plane is determined according to the Critical Direction Method proposed by Araújo et al. (2017). Such a plane is searched within all candidate planes containing the hot-spot $H$, and is characterised by the orientation $\alpha$ measured with respect to the $Z$-axis shown in Fig. 8. The hot-spot $H$ is assumed to be at one of the trailing edges, according to the experimental observations reported in Araújo and Nowell (2009). 

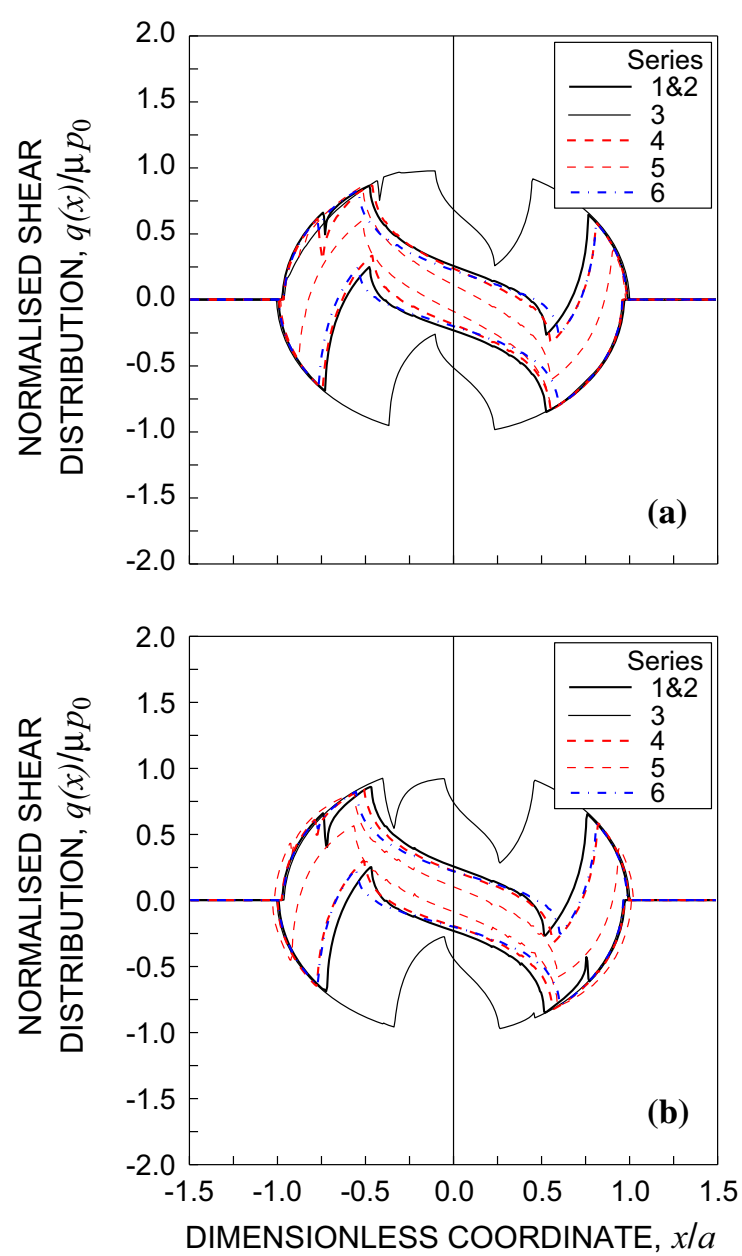

Fig. 7 Normalised contact shear stress distribution vs dimensionless coordinate $x / a$ : a linear elastic analysis without residual stresses, and b elastic-plastic analysis with residual stresses, for each loading condition examined (see Table 1)

Under a plane strain condition, such a plane can be represented by a segment, whose physical size is assumed to be equal to $2 d$, where $d$ is the average material grain size.

Within such candidate planes, the critical one is that maximising the averaged value of the fatigue parameter represented by an equivalent stress amplitude defined as follows:

$$
\begin{gathered}
\bar{N}_{e q, a}(\alpha)=\frac{1}{2 d} \int_{0}^{2 d} N_{a}(r, \alpha) d r+\frac{\sigma_{a f,-1}}{\sigma_{u}} \cdot \frac{1}{2 d} \int_{0}^{2 d} \\
N_{m}(r, \alpha) d r
\end{gathered}
$$

varying $\alpha$ in the range $-90^{\circ} \leq \alpha \leq+90^{\circ}$, where $(\alpha, r)$ are the coordinates in the radial frame $\mathrm{Hr} \alpha, N_{a}$

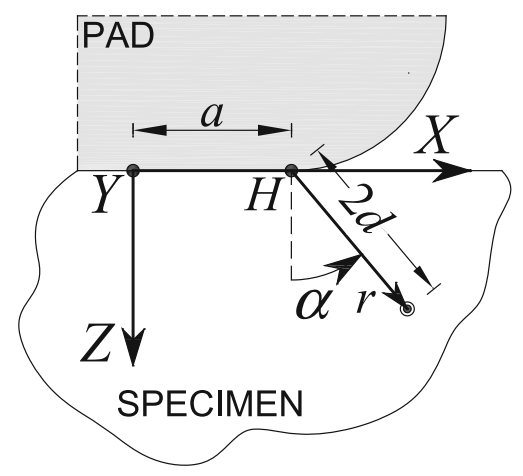

Fig. 8 Representation of the radial frame $H r \alpha$ and critical plane candidate

and $N_{m}$ are the amplitude and the mean value of the normal stress with respect to the plane with orientation $\alpha, \sigma_{a f,-1}$ is the material fatigue strength at a reference number $N_{0}$ of loading cycles (generally, $N_{0}$ is assumed to be equal to $2 \times 10^{6}$ cycles) under fully reversed normal loading, and $\sigma_{u}$ is the ultimate tensile strength of the material.

Once the critical plane has been determined (orientation $\alpha_{c r}$ ), the evaluated number of loading cycles to failure, $N_{c a l}$, is computed by solving the following equation through an iterative procedure:

$$
\begin{aligned}
& \sqrt{N_{e q, a}^{2}+\left(\frac{\sigma_{a f,-1}}{\tau_{a f,-1}}\right)^{2}\left(\frac{N_{c a l}}{N_{0}}\right)^{-\frac{2}{m}}\left(\frac{N_{0}}{N_{c a l}}\right)^{-\frac{2}{m *}} C_{a}^{2}} \\
& =\sigma_{a f,-1}\left(\frac{N_{c a l}}{N_{0}}\right)^{-\frac{1}{m}}
\end{aligned}
$$

where $C_{a}$ is the amplitude of the shear stress computed according to the Maximum Rectangular Hull method proposed by Araújo et al. (2014), $\tau_{a f,-1}$ is the material fatigue strength at a reference number $N_{0}$ of loading cycles under fully reversed shear loading, and $m$ and $m *$ are the slope of the $\mathrm{S}-\mathrm{N}$ curve under fully reversed normal loading and shear loading, respectively. Note that $N_{a}, N_{m}$ and $C_{a}$ in Eq.(3) are computed at the verification point with radial coordinates $\left(2 d, \alpha_{c r}\right)$.

The material properties needed to apply the criterion were not measured during the examined experimental campaign. Therefore, we have taken them from the literature related to a similar titanium alloy (Lin et al. 2018), as is listed in Table 2. 
Table 2 Mechanical and fatigue properties of Ti6Al4V alloy (Lin et al. 2018)

\begin{tabular}{lllllll}
\hline Material & $\sigma_{u}(\mathrm{MPa})$ & $\sigma_{a f,-1}(\mathrm{MPa})$ & $m$ & $\tau_{a f,-1}(\mathrm{MPa})$ & $m^{*}$ & $N_{0}(\mathrm{cycles})$ \\
\hline Ti6Al4V & 1005 & 287.98 & 5.78 & 149.64 & 5.78 & $2(10)^{6}$ \\
\hline
\end{tabular}

\subsection{Results}

The equivalent stress amplitude $\bar{N}_{e q, a}$, normalised with respect to its maximum value, against the orientation $\alpha$ is plotted in Fig. 9, for each loading condition listed in Table 1, by using both stress results from a linear elastic analysis in conjunction with the superposition principle (Fig. 9a) and those from an elastic-plastic analysis (Fig. 9b).

It can be noticed that the maximum values are attained in correspondence to $\alpha=-5^{\circ}$ and $\alpha=-10^{\circ}$. In Araújo and Nowell (2009), the experimental crack path is reported for only one specimen of Series No. 5, and it is initially inclined about $-10^{\circ}$ (main primary crack). Such an experimental data is in quite good agreement with the critical plane orientation (which is assumed to correspond to the crack initiation orientation according to the proposed criterion), computed to be equal to $5^{\circ}$ for Series No. 5, regardless of FE analysis type.

The experimental fatigue life $N_{\text {exp }}$ is plotted against the evaluated one $N_{c a l}$ in Fig. 10, by employing both stress results from a linear elastic analysis in conjunction with the superposition principle (Fig. 10a) and those from an elastic-plastic analysis (Fig. 10b).

The evaluated results are in quite good agreement with the experimental ones, all results falling into the scatter band 3. The fatigue lives computed in Araújo and Nowell (2009) are also reported in Fig. 10b. The accuracy of the evaluations is quantified by means of the root mean square error (Lagoda and Walat 2014; Vantadori et al. 2018), equal to 1.14 for the present study results and to 3.26 for the results in Araújo and Nowell (2009).

\section{Conclusions}

Considering the proposed crack initiation life methodology, the main conclusions which can be drawn from this research work are the following:

(1) The results in terms of both crack initiation path and evaluated fatigue life are independent of the
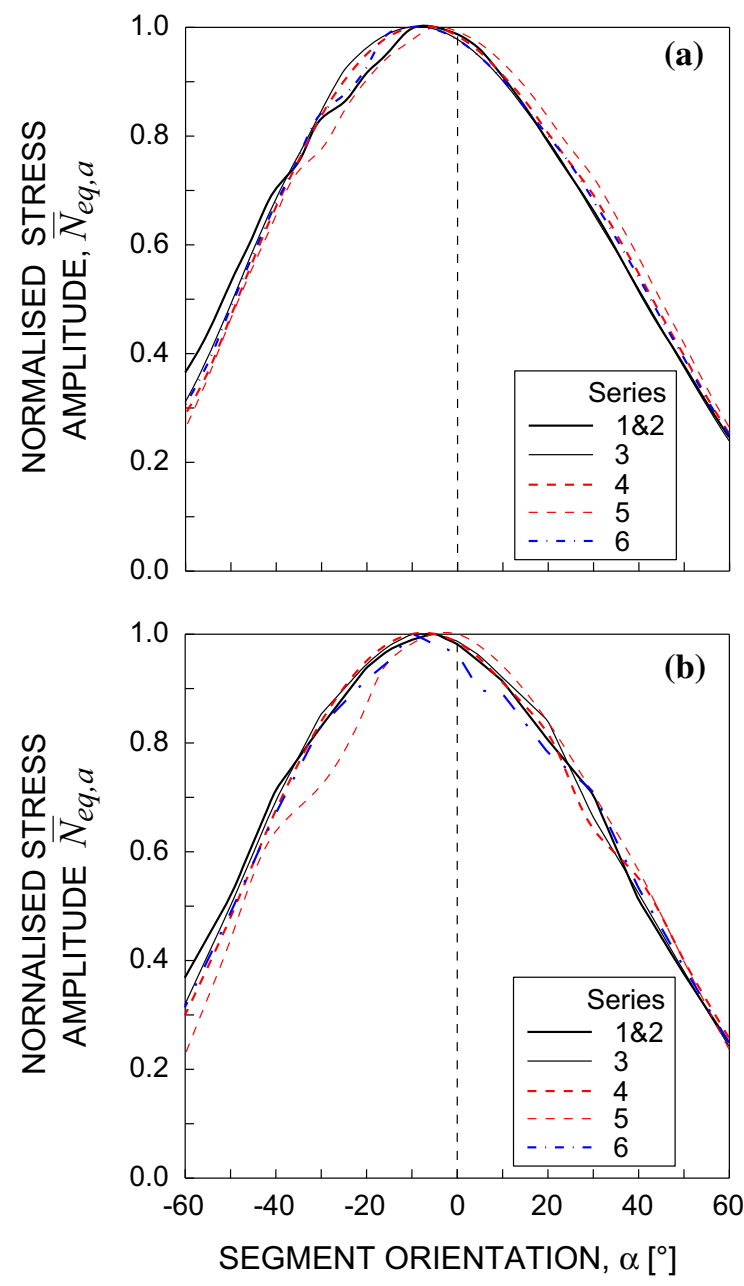

Fig. 9 Normalised equivalent stress amplitude vs segment orientation $\alpha$ : a linear elastic analysis in conjunction with the superposition principle, and $\mathbf{b}$ elastic-plastic analysis, for each loading condition examined (see Table 1)

FE analysis type employed to compute the stress field in the specimen;

(2) An accurate simulation of the shot peening effect on the fretting fatigue life would require the knowledge of several factors such as: the actual residual stress depth profile, the elastic-plastic mechanical behaviour of the material under cyclic loading, the 

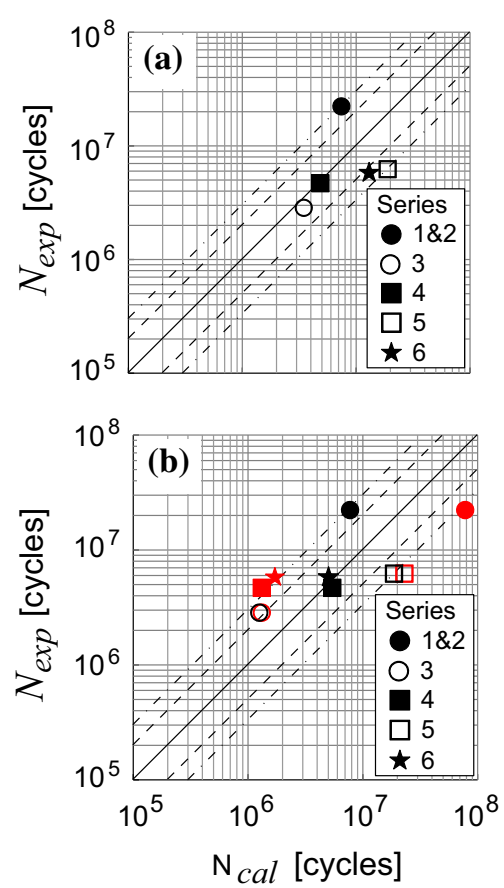

Fig. 10 Experimental fatigue life $N_{\text {exp }}$ against computed fatigue life $N_{c a l}$ : a linear elastic analysis in conjunction with the superposition principle, and $\mathbf{b}$ elastic-plastic analysis, for each loading condition examined (see Table 1). In Fig. 10b, the symbols in red refer to results by Araújo and Nowell (2009).

residual stress relaxation under fatigue, and many others. Since a linear elastic FE analysis is less time consuming than an elastic-plastic one, a linear elastic analysis in conjunction with the residual stress profile (proposed by some of the present authors) has been herein shown to be a useful tool for the structural assessment of shot peened and fretted engineering components;

(3) Conservative and non-conservative evaluations have been obtained. In the worst case, the life evaluations vary by a factor equal to 3.00 when compared to the experimental life.

Acknowledgements Open access funding provided by Università degli Studi di Parma within the CRUI-CARE Agreement.

Funding Open access funding provided by Università degli Studi di Parma within the CRUI-CARE Agreement.

Open Access This article is licensed under a Creative Commons Attribution 4.0 International License, which permits use, sharing, adaptation, distribution and reproduction in any medium or format, as long as you give appropriate credit to the original author(s) and the source, provide a link to the Creative Com- mons licence, and indicate if changes were made. The images or other third party material in this article are included in the article's Creative Commons licence, unless indicated otherwise in a credit line to the material. If material is not included in the article's Creative Commons licence and your intended use is not permitted by statutory regulation or exceeds the permitted use, you will need to obtain permission directly from the copyright holder. To view a copy of this licence, visit http://creativecommons.org/licenses/ by/4.0/.

\section{References}

Araújo JA, Nowell D (2009) Mixed high low fretting fatigue of Ti6Al4V: tests and modelling. Tribol Int 42:1276-1285

Araújo JA, Carpinteri A, Ronchei C, Spagnoli A, Vantadori S (2014) An alternative definition of the shear stress amplitude based on the maximum rectangular hull method and application to the C-S (Carpinteri-Spagnoli) criterion. Fract Eng Mater Struct 37:764-771

Araújo JA, Almeida GMJ, Ferreira JLA, da Silva CRM, Castro FC (2017) Early cracking orientation under high stress gradient: the fretting. Int J Fatigue 100:302-311

Boller C, Seeger T (1987) Material data for cyclic loading. PART D: aluminium and titanium alloys. Mater. Sci. Monogr., Elsevier Science Publisher B.V. Amsterdam, The Netherlands

Calcaterra JR, Golden PJ (2006) A fracture mechanics life prediction methodology applied to dovetail fretting. Tribol Int 39:1172-80

Carpinteri A, Vantadori S, Zanichelli A (2019) Lifetime estimation of mechanical assemblies under constant amplitude fretting fatigue loading. Fatigue Fract Eng Mater Struct 42:1927-1936

Chan KS, Lee Y-D, Davidson DL (2001a) A fracture mechanics approach to high cycle fretting fatigue based on the worst case fret concept. I. Model development. Int J Fract 112:299-330

Chan KS, Davidson DL, Owen TE, Lee Y-D, Hudak SJ Jr (2001b) A fracture mechanics approach to high cycle fretting fatigue based on the worst case fret concept. II. Experimental evaluation. Int J Fract 112:331-353

Farrahi GH, Lebrun JL, Couratin D (1995) Effect of shot peening on residual stress and fatigue life of a spring steel. Fatigue Fract Eng Mater Struct 18:211-220

Fouvry S, Kapsa Ph, Vincent L (1995) Analysis of sliding behaviour for fretting loadings: determination of transition criteria. Wear 185:35-46

Gao YK, Yao M, Li JK (2002) An analysis of residual stress fields caused by shot peening. Metall Mater Trans A 33A:1775

Hamada S, Zhang K, Koyama M, Ueda M, Noguchi H (2020) Fatigue crack propagation modes: plastic deformation mode and damage accumulation mode. Int J Fract 222:111-122

Higounenc O (2005) Correlation of shot peening parameters to surface characteristic. In: Proceedings of the 9th International Conference on Shot Peening, Paris, p 2005047

Hills DA, Nowell D (1994) Mechanics of fretting fatigue. Kluwer Academic Publishers, Dordrecht

International ASM, Friction, lubrication, and wear technology, vol 18, Totten G.E. (eds) (2017) Materials Park. Ohio, USA 
Kapsa P (2011) Environmental effects in fretting. In: Landolt D, Mischler S (eds) Tribocorrosion of passive metals and coatings, 1st edn. Woodhead Publishing, Cambridge, pp 100117

Kirk D (2014) Estimate compressed layer depth by using Almen peening intensity. Shot Peener 28(2):30-38

Korsunsky AM (2017) A teaching essay on residual stresses and eigenstrains. Elsevier/Butterworth-Heinemann, Oxford

Lagoda T, Walat K (2014) Lifetime of semi-ductile materials through the critical plane approach. Int J Fatigue 67:73-7

Lin J, Li W, Yang S, Zhang J (2018) Vibration fatigue damage accumulation of Ti-6Al-4V under constant and sequenced variable loading conditions. Metals 8(296):1-13

Liu Z, Zakoworotny M, Guo J, Zehnder AT, Hui C-Y (2020) Energy release rate of a single edge cracked specimen subjected to large deformation. Int J Fract 226:71-79

Mangardich D, Abrari F, Fawaz Z (2019) A fracture mechanics based approach for the fretting fatigue of aircraft engine fan dovetail attachments. Int J Fatigue 129:105213

Martín V, Vázquez J, Navarro C, Domínguez J (2020) Effect of shot peening residual stresses and surface roughness on fretting fatigue strength of Al 7075-T651. Tribol Int 142:106004

Murugesan J, Mutoh Y (2014) Fretting fatigue strength prediction of dovetail joint and bolted joint by using the generalized tangential stress range-compressive stress range diagram. Tribol Int 76:116-121

Papanikos P, Meguid SA (1994) Theoretical and experimental studies of fretting-initiated fatigue failure of aeroengine compressor discs. Fatigue Fract Eng Mater Struct 17(5):539-550

Papanikos P, Meguid SA, Stjepanovic Z (1998) Threedimensional non-linear finite element analysis of dovetail joints in aero engine discs. Finite Element Anal Des 29:17386

Pereira K, Vanegas-Useche LV, Wahab MA (2020) Aspects of fretting fatigue finite element modelling. Comput Mater Continua 64:97-144

Rajasekaran R, Nowell D (2006) Fretting fatigue in dovetail blade roots: experiment and analysis. Tribol Int 39:1277-85

Sabelkin V, Martinez SA, Mall S, Sathish S, Blodgett MP (2005) Effects of shot-peening intensity on fretting fatigue crackinitiation behaviour of Ti-6Al-4V. Fract Eng Mater Struct 28:321-332

Sun S, Li L, Yue Z, Yang W, He K, Li S (2020) Fretting fatigue failure behavior of Nickel-based single crystal superalloy dovetail specimen in contact with powder metallurgy pads at high temperature. Tribol Int 142:105986

Sunde SL, Haugen B, Berto F (2021) Experimental and numerical fretting fatigue using a new test fixture. Int $\mathrm{J}$ Fatigue $143: 106011$
Simo JC, Laursen TA (1992) An augmented lagrangian treatment of contact problems involving friction. Comput Struct 42:97-116

Vantadori S, Zanichelli A (2020) Fretting-fatigue analysis of shot-peened aluminium and titanium test specimens. Fatigue Fract Eng Mater Struct. https://doi.org/10.1111/ffe. 13367

Vantadori S, Carpinteri A, Fortese G, Ronchei C, Scorza D, Zanichelli A (2018) Fatigue lifetime evaluation of notched components: implementation of the control volume concept in a strain-based LCF criterion. Theoret App Fract Mech 97:400-408

Vantadori S, Carpinteri A, Iturrioz I (2019) Fretting failure of a pressure armour in an unbonded flexible riser. Int J Fatigue 128:1-8

Vantadori S, Zanichelli A, Araújo JA (2020a) Fretting fatigue of 7050-T7451 Al alloy: the influence of bulk mean stress. Int J Fatigue 140:105816

Vantadori S, Vázquez J, Zanichelli A (2020b) Fretting fatigue and shot peening: a multiaxial fatigue criterion including residual stress relaxation. Tribol Int 151:106537

Vázquez J, Navarro C, Domínguez J (2016) Two dimensional versus three dimensional modelling in fretting fatigue life prediction. J Strain Anal Eng Des 51:109-17

Vázquez J, Carpinteri A, Bohórquez L, Vantadori S (2019) Fretting fatigue investigation on Al 7075-T651 alloy: experimental, analytical and numerical analysis. Tribol Int 135:478-87

Yang Q, Zhou W, Zhong Y, Zhang X, Fu X, Chen G, Li Z (2018) Effect of shot-peening on the fretting wear and crack initiation behavior of Ti-6Al-4V dovetail joint specimens. Int $\mathbf{J}$ Fatigue 107:83-95

Yuan R, Liao D, Zhu SP, Yu ZY, Correia JAFO, de Jesus AMP (2021) Contact stress analysis and fatigue life prediction of turbine disc-blade attachment with fir-tree tenon structure. Fatigue Fract Eng Mater Struct. https://doi.org/10.1111/ffe. 13410

Zanichelli A, Vantadori S (2020) Shot-peened fretting fatigue components: endurance strength and fatigue life assessment. Mater Des Process Commun. https://doi.org/10. 1002/mdp2.196

Zhou ZR, Liu QY, Zhu MH, Tanjala L, Kapsa P, Vincent L (2000) An investigation of fretting behaviour of several metallic materials under grease lubrication. Tribol Int 33:69-74

Publisher's Note Springer Nature remains neutral with regard to jurisdictional claims in published maps and institutional affiliations. 